\title{
Teaching and research: Specificity and congruence of university faculty achievement goals
}

\author{
Martin Daumiller \\ University of Augsburg
}

\author{
Markus Dresel \\ University of Augsburg
}

\begin{abstract}
Teaching and research are core tasks of university faculty. Previous research has documented the power of achievement goal theory for describing university scholars' motivations. For theory, research, and practical implications it is crucial to have knowledge about the separability, as- sociations, differences, and interplay of scholars' goals for teaching and research. Hence, we report two studies with 1151 and 771 German university scholars. We found that their goals can be separated between both domains while sharing a substantial amount of variance (26-67\%). Besides general differences in goal pursuit (more functional in the research domain, more variability in the teaching domain), the congruence of goal pursuit between both domains was associated with work stress, job satisfaction, and beliefs about the teaching-research-nexus.
\end{abstract}

Keywords: Faculty motivation, Achievement goals, Teaching, Research, Domain specificity, Stability

(C) 2020, Elsevier Ltd. The official citation for this manuscript is: Daumiller, M., \& Dresel, M. (2020). Teaching and research: Specificity and congruence of university faculty achievement goals. International Journal of Educational Research, 99, 101460. https://doi.org/10.1016/j.ijer.2019.08.002. This paper is not the copy of record and may not exactly replicate the final, authoritative version of the article. The final article will be available, upon publication, via its DOI.

University faculty's core tasks are teaching and research. First, reliable evidence indicates that scholars' motivations are an important personal factor for their cognition and behavior (for an overview see Daumiller, Stupnisky, \& Janke, 2020). These motivations can be described using Achievement Goal Theory (AGT), for example, by characterizing their motivation as more or less strong strivings towards task mastery and competence development or towards superiority and competence demonstration. In doing so, previous research has solely regarded achievement goals in the teaching domain, or the research domain, or the overall university work context without simultaneously addressing the teaching and the research domain and differentiating between them.

However, while teaching and research are central and time-intensive aspects of university scholars' work, they are rather distinct work contexts: Teaching primarily focuses on imparting existing knowledge to others,

Correspondence concerning this article should be addressed to Martin Daumiller, Department of Psychology, University of Augsburg, Universitätsstr. 10, 86135 Augsburg, Germany; Martin.Daumiller@phil.uni-augsburg.de.

We have no known conflicts of interest to disclose.

The study presented in this paper was funded by a grant from the German Research Foundation (Deutsche Forschungsgemeinschaft; DFG) to Markus Dresel (DR 454/8-1). and research focuses on creating and documenting new knowledge. Besides being different achievement contexts, teaching and research are also different social contexts (with social interaction being constituent of teaching, but research often being able to be conducted without direct interaction with others). As such, teaching and research often involve distinct tasks that are directed at different outcomes (Marsh \& Hattie, 2002). Furthermore, teaching and research often have different relevance and priority for individuals and their career (e.g., Marsh \& Hattie, 2002; Smeby, 1998), and junior faculty do not often decide on a university career because of equal interest in both domains (McAlpine \& Akerlind, 2010). As such, it stands to reason that scholars' motivations, in the form of their achievement goals, need not be the same in both domains. This reasoning is in line with other works in the field that investigated the motivations of specific faculty groups by analyzing both domains separately (e.g., Stupnisky, Hall, Daniels, \& Mensah, 2017), however this claim has not yet been explicitly investigated. This research gap needs to be addressed, as the separability of motivational constructs, such as achievement goals for teaching and research, is an important aspect for theory, research, and practical interventions.

Specifically, regarding achievement goals, knowledge on the specificity of goals between teaching and research is essential for (a) the degree of specificity 
to which achievement goals should be conceptualized and measured, (b) the choice and measurement of other (dependent or independent) variables, (c) ensuring that empirical investigations use an appropriate research design that adequately incorporates the work domains, (d) interpreting research findings adequately, as well as (e) deriving appropriate practical implications that are based on the optimal level of specificity (see Murphy \& Alexander, 2000, and Praetorius et al., 2014, for a similar reasoning regarding temporal stability). Building on goals separability, it is, in light of the aforementioned aspects, also very important to have further information regarding their associations and the extent to which there are general differences in the achievement goals between both domains, as well as to what extent individuals pursue their goals similarly between both domains (and how this relates to their cognition and behaviors). In the present work, we set out to investigate these research aims by conducting two studies on the domain specificity of goals (separability, associations, and differences in goal pursuit) and the extent of the congruence of teaching goals and research goals and its associations to scholars' work stress, job satisfaction, and subjective perceptions of the teaching-research nexus (i.e., how integrated and synergistic scholars perceive teaching and research to be).

On a more general level, investigations of the context specificity of achievement goals are rather rare in AGT research (for investigations of students' achievement goals regarding different subjects, see Bardach, Yanagida, Schober, \& Lüftenegger, 2018; Bong, 2001, 2004; Sparfeldt et al., 2015; Sparfeldt, Buch, Wirthwein, \& Rost, 2007) and relatively little is known about the specificity of achievement goals across different domains. As teaching and research are two rather distinct (but fairly equal in terms of job characterization) work domains of university scholars, they are a prime paradigm for investigations of the domain specificity of achievement goals. As such, the research aims of the current study are not only highly relevant for theory, research, and practical interventions regarding university scholars' motivations, but also for AGT in general.

\section{University scholars' achievement goals for teach- ing and research}

Teaching and research each constitute explicit achievement contexts in which scholars are required to deliver high-quality outcomes, successfully perform under observation, and constantly learn and improve. As such, AGT can be considered a useful framework to explain individuals' motivations therein.
Achievement goals are cognitive representations of competence-related end states in achievement contexts that an individual is committed to either approach or avoid (Elliot, 2005; Hulleman, Schrager, Bodmann, \& Harackiewicz, 2010). Different affective, cognitive, and behavioral consequences have been documented for preferences for different goals in diverse populations, such as students, athletes, and teachers (Hulleman et al., 2010; Payne, Youngcourt, \& Beaubien, 2007). Lately, AGT has also successfully been used to describe the motivations of university scholars (Daumiller \& Dresel, 2020; Daumiller, Dickhäuser, \& Dresel, 2019; Daumiller, Figas, \& Dresel, 2015; Daumiller, Grassinger, Dickhäuser, \& Dresel, 2016; Janke \& Dickhäuser, 2018; Janke, Rudert, \& Daumiller, 2018). These research works documented that university scholars report pursuing different achievement goals that can empirically be considered as distinct from each other and that are differentially associated with aspects of their cognition and behavior (such as attitudes towards help-seeking, experience of positive affect, learning behaviors, and questionable research practices) as well as students' assessments of teaching quality and their learning outcomes. In doing so, these investigations regarded achievement goals in the teaching domain (Daumiller et al., 2019; Daumiller et al., 2015; Daumiller et al., 2016), or the research domain (Daumiller \& Dresel, 2020; Janke et al., 2018), or the overall university work context without distinguishing between teaching and research (Janke \& Dickhäuser, 2018).

While achievement goals were originally considered as goal orientations, that is, rather stable, trait-like orientations towards certain goals across different contexts and domains (e.g., Silva \& Nicholls, 1993; in part because they are assumed to stem from largely stable, implicit theories about one's own intelligence, Dweck \& Leggett, 1988), motivation literature has moved towards a more domain-specific viewpoint (Murphy \& Alexander, 2000). In this light and given the current understanding within AGT, achievement goals are simultaneously considered to be partly global and partly domain-specific (e.g., Bong, 2001, 2004; Middleton \& Midgley, 1997; Pintrich, 2000; Sparfeldt et al., 2015; Sparfeldt et al., 2007). This is also reflected within the definition provided above (preferences for different end-states in achievement contexts). As teaching and research are contexts within the academic realm which share multiple features (e.g., institutional embeddedness, complexity of tasks, being challenging, requiring comprehensive expertise and competences), partly similar goal setting processes can be expected. 
However, as the achievement and social contexts of teaching and research can, as described before, to a substantial extent be considered different from each other, it stands to reason that also their achievement goals can be different for both domains (different goal endorsement due to different features of the achievement environment; see Fryer \& Elliot, 2007). This assumption is additionally supported empirically by first studies from two different lines of research: AGT research based on students in schools, and studies into the motivation of university scholars.

For students, there are investigations regarding the specificity of achievement goals across different subjects (2004, Bong, 2001; Sparfeldt et al., 2015; Sparfeldt et al., 2007). Here, empirical findings attested to the separability of achievement goals for the different school subjects (Bong, 2001; Sparfeldt et al., 2007) and pointed to correlations across the subjects ranging from $r_{\text {mean }}=.41$ to $r_{\text {mean }}=.79$ (Sparfeldt et al., 2015; very similar to Bong, 2004), with mastery goals being more school-subject specific than performance goals (Bong, 2004; Sparfeldt et al., 2015) and also approach-based goals being more subject specific than avoidance based goals (Sparfeldt et al., 2007). Theoretically, these differences in goal specificity are sensible and can also be expected for university scholars, as for instance learning opportunities and contents vary substantially between teaching and research and preferences for avoidance goals may be more due to personality stable fractions such as fear of failure than approach goals.

Regarding university scholars' motivations, there are only a few investigations that have examined teaching and research simultaneously. However, the existing research works agree that the motivations for teaching and research can be presumed to be separate from each other. By symmetrically running identical analyses in both the teaching and the research domain, Stupnisky et al. (2017) investigated in a specific segment of university scholars (pretenure faculty) how need fulfillment is a mediator of balance, expectations, and collegiality on professional success. The authors found mean level differences in need fulfillment between both domains along with partly different mediation effects, which strengthens the assumption of distinct motivations in both fields for the analyzed population (however, they did not test whether the needs can actually be separated between both domains and how strongly they are associated with each other). First indications for the actual separability of motivational constructs between both domains were reported by Bailey (1999) who presented factor analytic results indicating that teaching and research self-efficacy beliefs can be separated from each other (see also Zhang, Fu, Li, \& He, 2019, and Ismayilova \& Klassen, 2019). Finally, professional success. The authors found mean level differences in need fulfillment between both domains along with partly different mediation effects, which strengthens the assumption of distinct motivations in both fields for the analyzed population (however, they did not test whether the needs can actually be separated between both domains and how strongly they are associated with each other). First indications for the actual separability of motivational constructs between both domains were reported by Bailey (1999) who presented factor analytic results indicating that teaching and research self-efficacy beliefs can be separated from each other (see also Zhang, Fu, Li, \& He, 2019, and Ismayilova \& Klassen, 2019). Finally, Mägi and Beerkens (2016) argued that scholars differ in whether their intrinsic interest lies more strongly within teaching, within research, or equally within both, with the latter being especially relevant for effective teaching behaviors (in the form of research-related teaching). Taken together, this shows that the motivations for teaching and research, and in particular their respective achievement goals, can be assumed to be separable from each other, while at the same time little is known regarding their differences and interplay.

Humboldt's idea of the university entails that it is a place in which researchers are also teachers and that teachers are also researchers (Östling, 2018). While academic jobs at universities typically have teaching and research requirements, the balance between these two responsibilities can differ substantially between institutions (e.g., teaching vs. research focused universities) and different ranks (e.g., adjunct faculty vs. tenuretrack professors). From an international perspective, teaching and research can be considered rather balanced in Germany, Humboldt's home country (Östling, 2018). In the German higher education system, graduate students pursuing a Ph.D. usually have - in comparison to, for example, the US-a master's degree already and are typically part of the academic staff. Specifically, they are often hired with at least a half-time contract as a faculty member, entailing both teaching and research responsibilities (see Wosnitza, Helker, \& Lohbeck, 2014, for a more detailed description). This information should be borne in mind as the present research is based on a German sample. With teaching and research likely being rather closely aligned for this population, it is very well suited for investigations into the separability of scholars' motivations for teaching and research. Motivations for teaching and research being separable in this context can be taken as strong support 
for the generalizability of these findings-also into contexts where teaching and research are more unequally weighted. Following this reasoning, we also use the term "university scholars" instead of "post-secondary academic staff" to emphasize that they are engaged in both teaching and research. Despite the differences that might be due to the context (such as institutions and ranks), substantial individual differences in how scholars weigh, perceive, and are motivated in teaching and research likely remain.

Regarding the goal striving processes, general differences between the teaching and research domains are plausible. As research in comparison to teaching is often more prioritized by faculty (e.g., Marsh \& Hattie, 2002; Smeby, 1998) and is considered central to prestige and the allocation of temporal and financial resources (e.g., also in Germany, for employment and tenure decisions, research performance is typically weighted more heavily than teaching performance; Backes-Gellner \& Schlinghoff, 2010; Leisyte, Enders, $\&$ de Boer, 2009), scholars can be expected to focus on adaptive goal pursuit in this domain more strongly by pursuing stronger learning goals and less work avoidance goals, and to vary more in the goals they pursue in the teaching domain.

This reasoning also shows that aside from such general trends, it is possible that for some individuals, their achievement goals are similar between both domains, whereas for other individuals, different goals might be prioritized in both domains. This implies that individuals likely differ in the extent to which their prioritized goals for teaching and goals for research align. We term this alignment of goals between teaching and research goal congruence. ${ }^{1}$ This amount of convergence in goal prioritization between both domains is conceptually similar and related to the congruence of a person's goals with their interests and core values, which has been described by Sheldon and Elliot (1999) in their self-concordance model. This model suggests that individuals are likely to set "self-concordant" goals (i.e., goals that are consistent with a person's interests and values), which positively influence goal attainment and subsequent well-being (empirical findings on the positive effects of goal concordance are summarized in Kehr, 2004). From this, two conclusions can be drawn:
First, just as individuals set goals in congruence to their interests and core values, it can be expected that individuals pursue goals in congruence to goals from another, related domain. Second, goals in different domains can be expected to be pursued "self-concordantly" and as such, in turn, be congruent with each other (similar goals in different domains due to a common, self- concordant basis). In consequence, goal congruence between teaching and research can be expected to be relevant for goal attainment and well-being, and consequently matter for aspects such as work-stress and job satisfaction-particularly because incongruent goals also likely lead to more experienced goal conflicts (see Boudreaux \& Ozer, 2013; Gorges, Esdar, \& Wild, 2014. Furthermore, given the nature of their job, scholars often shift between teacher and researcher roles. These shifts can be assumed to be less stressful, the more similar the two roles are, also in terms of their therein pursued goals. At the same time, goal congruence can be expected to be associated with scholars' appraisals of to what extent teaching and research go together with each other and function synergistically (i.e., their subjective perceptions of the teaching research nexus; Coate, Barnett, \& Williams, 2001; Daumiller \& Dresel, 2018; Jucks \& Hillbrink, 2017): For instance, assuming a low synergy between both domains might lead to prioritization of one domain over another (see also Bak, 2015), and consequently be associated with low goal congruence between teaching and research. To understand the interplay of goals between teaching and research in form of their goal congruence better, we therefore set out to investigate its associations with work-stress, job satisfaction, and subjective perceptions of the teaching-research nexus.

\section{Achievement goal framework underlying the pre- sent work}

In AGT, different goal classes are distinguished. Original definitions (e.g., Dweck, 1986; Nicholls, 1984) regarded mastery goals (focused on developing competence and acquiring task mastery) and performance goals (focused on demonstrating competence and outperforming others). Subsequently, a valence dimension was included in order to distinguish between

\footnotetext{
${ }^{1}$ N.b.: With goal congruence, we focus our view on the interplay between teaching and research motivations and describe the extent to which these motivations are similar to each other. We suggest that more similar goals between both domains are more functional. However, following Hofer and Fries (2016), it would also be possible to expect that pursuing strong goals in both domains (opposed to only pursuing strong goals in one domain, but not the other) might, beyond the compatibility of individual goals, as a function of resource conflicts, cause more goal conflictions that could in turn negatively affect achievement and well-being (see Gorges \& Grund, 2017). We believe that this latter perspective is more relevant for rather disjoint achievement contexts, such as school and leisure time, and consider the former perspective most helpful in closer and more overlapping contexts, such as teaching and research.
} 
goals focused on approaching success or avoiding failure (Elliot \& Harackiewicz, 1996), leading to mastery approach, mastery avoidance, performance approach, and performance avoidance goals (Elliot \& McGregor, 2001). Further, it has been suggested that a finer differentiation and a disentanglement, based on the content of mastery and performance based goals, is necessary (Brophy, 2005; Elliot, 2005; Grant \& Dweck, 2003; Hulleman et al., 2010). Regarding performance goals, an appearance component (wanting to be perceived as competent or not wanting to be perceived as incompetent, irrespective of personal performance) and a normative component (wanting to be more competent than others or not worse than others concerning actual performance) can be distinguished (Elliot, 1999, 2005; Hulleman et al., 2010; Lee \& Bong, 2016; Senko \& Dawson, 2017; Urdan \& Mestas, 2006). Also mastery goals can be distinguished further (e.g., Elliot, Murayama, \& Pekrun, 2011), according to whether the standard for evaluating one's own competence lies in the task (named task goals throughout this manuscript) or in one's intrapersonal development (named learning goals throughout this manuscript). Lastly, two further goal classes have been proposed that have been shown to hold great relevance in the teaching and work context (see for example Butler, 2012; Butler \& Shibaz, 2008; King \& McInerney, 2014): work avoidance goals (striving to get through the day with little effort) and relational goals (striving to create close and caring relationships).

Daumiller et al. (2019) focused on these finer differentiations of achievement goals and summarized them in an overview model. Herein, the authors distinguished six different types of goal content (learning, task, normative, and appearance, as well as the work avoidance and relational aspects). For each of the two facets of mastery goals and performance goals, an approach and an avoidance component is postulated (while work avoidance goals are avoidance-based by definition, and relational goals are conceptualized as approach-based goals). These assumptions result in a framework with ten theoretically distinguishable goal classes.

While the needs and merits of this distinction and the classification of the above described goals is beyond the scope of the present investigation and can also be controversially discussed (e.g., Murayama, Elliot, \& Friedman, 2012), they represent the breadth of aspects that can be well and meaningfully distinguished. Beside this, in interviews, all of these goal classes have been found to be reported by university scholars when asked about their personal goals for teaching, as well as their personal goals for research; while their differential relevance for scholars' cognition and behavior was also attested (summarized in Daumiller et al., 2019, and Daumiller \& Dresel, 2020). Taken together, this framework can therefore be regarded as very relevant for describing the motivations of university scholars and is especially important for research investigations such as the present work (to ensure a valid interpretation of its findings).

\section{Research questions and hypotheses}

The purpose of the present work was to investigate university scholars' achievement goals for teaching and research. Specifically, we strove to investigate the domain specificity of achievement goals by examining their separability and associations as well as differences in goal pursuit between teaching and research. Based upon that, we wanted to elucidate the extent of goal congruence between teaching and research and how it relates to scholars' work stress and job satisfaction as well as subjective perceptions of the teaching-research nexus.

Based on the arguments provided in the previous sections, the main hypotheses guiding our research were:

H1. University scholars' achievement goals can be separated between the teaching and the research domain. Specifically, we expected for each goal class a model with two factors (distinguishing between teaching and research) to describe the data better than an undifferentiated single factor model.

H2. For each goal class, there is a substantial amount of shared variance between teaching and research, but also a substantial portion of domain specificity (indicated by moderate to strong correlations between the goals), which varies between the different goal classes. Specifically, based on the previous findings on domain specificity in students and theorizing about the nature of goal pursuit, we expected a higher context specificity of

(a) mastery based goals compared to performance based goals as well as

(b) approach based goals compared to avoidance based goals.

H3. Achievement goals differ between the teaching and the research domain in the average strength of goal striving and the extent of interindividual differences within them. Specifically, based on the different prioritization of teaching and research by faculty, we expected 
(a) stronger mastery based and less work avoidance goals for the research than the teaching domain and

(b) more variability in the teaching than in the research domain.

H4. The amount of goal congruence (i.e., the person-specific association of the goals for teaching with the goals for research) substantially varies between instructors and is

(a) negatively associated with work stress,

(b) positively associated with job satisfaction,

(c) and positively associated with subjective perceptions of the teaching-research nexus.

The core assumption behind these hypotheses is that the achievement goal framework works equally well for the teaching as it does for the research domain, that is, that measurement invariance is demonstrated across these two domains. Specifically, for $\mathrm{H} 1$ and $\mathrm{H} 2$ it is necessary that the factor structure is the same across both domains (configural invariance), and for $\mathrm{H} 3$ and $\mathrm{H} 4$ it is additionally required that also factor loadings and the intercepts of the item indicators are equivalent between both domains (scalar invariance). Before investigating our hypotheses, we therefore first confirmed the assumption of measurement invariance between teaching and research.

\section{Overview of the present research}

To answer our research questions, we conducted two empirical studies. ${ }^{2}$ In Study 1, we examined measurement invariance and investigated the separability, associations, and differences in goal pursuit between teaching and research $(\mathrm{H} 1, \mathrm{H} 2$, and $\mathrm{H} 3)$. In Study 2, we tested the robustness of these findings by conducting the same analyses again and seeking to replicate the findings (Simons, 2014), while including an even broader sample. Based on that, we investigated the goal congruence and its associations with scholars' work stress, job satisfaction, and perceptions of the teachingresearch nexus (H4).

In both studies, university scholars responded to an online questionnaire assessing their achievement goals (Study 1 and 2) as well as work stress, job satisfaction, and subjective perceptions of the teaching-research nexus (Study 2) and relevant biographic in- formation. In both studies, the participants received a small incentive after having completed the study ( $5 €$ voucher). To recruit the samples, we chose typical fields that represent a range of university study programs, identified all public universities in Germany that taught these subjects, and randomly selected scholars from each university whom we subsequently contacted by e-mail. We used different subjects for Study 1 and Study 2 in order to focus on two distinct populations.

Both studies were conducted in full accordance with the Ethical Guidelines of the German Association of Psychologists and the American Psychological Association. Full anonymity was assured. We had no reason to assume that completing our survey would have any negative effects on the participants.

Comparing the descriptive composition (age, gender, and status group) of both samples with nationwide statistics (Statistisches Bundesamt, 2014) indicated that they represent the investigated fields of interest well.

\section{Study 1}

\subsection{Method}

\subsubsection{Procedure and sample}

1151 university scholars $(26.7 \%$ full professors, $36.7 \%$ academic staff with $\mathrm{PhD}, 36.7 \%$ academic staff without $\mathrm{PhD}$; males: $55.3 \%$, females: $44.7 \%$; mean age: 37.5 years; from the fields Physics: $32,2 \%$, History: $29,5 \%$, Psychology: $38.3 \%$ ) from 76 public German universities participated in the study.

\subsubsection{Measurement of achievement goals for teaching and research}

We used the questionnaire from Daumiller et al. (2019) to assess the achievement goals for teaching and research. This questionnaire narrowly focuses on the core of the goals' definitions, which is why it can easily be transferred to the research context by changing the item stem and a few key words (e.g., "researcher" instead of "instructor"; see Daumiller \& Dresel, 2020). This way, we had two scales that are symmetrical for the teaching and research domain.

We asked the participants to refer their answers exclusively to their teaching and research activities, respectively, using the item stems "In my current teaching activities, ..." and "In my current research activities, ...”. We measured task approach goals (“... I want to fulfill the different requirements very well"), task

\footnotetext{
${ }^{2}$ Specifically, this study is based on data that has partly already been reported on in previous work. Study 1 uses data from Daumiller et al. (2019), and Study 2 uses data from Daumiller and Dresel (2020), and extends each of these works by also including the achievement goals for the respective other domain.
} 
avoidance goals ("... I want to avoid fulfilling the different requirements poorly"), learning approach goals ("... my goal is to expand my professional and methodological knowledge as much as possible"), learning avoidance goals ("... my goal is not to leave the opportunities to expand my professional and methodological knowledge untapped”, appearance approach goals (“... I want to be perceived as competent"), appearance avoidance goals ("... I want to avoid being perceived as incompetent"), normative approach goals ("... my goal is to teach / do research better than my colleagues"), normative avoidance goals (“... my goal is to not teach / do research worse than my colleagues"), work avoidance goals ("... it is my goal to have the least amount of work as possible"), and relational goals ("... it is important to me to achieve a personal connection with my students / colleagues"). The scale has symmetrical wording between approach and avoidance goals. As these lead to shared method variance due to symmetric wording, we modeled correlated errors between the corresponding items (see Brown, 2014). There were four items for each type of goal class for each domain; all were answered on Likert-type scales ranging from 1 (do not agree at all) to 8 (agree completely). Internal reliability coefficients were very satisfactory and are reported in Table 1.

\subsubsection{Analyses}

Table 1

Descriptive Statistics and Correlations for the Achievement Goals for Teaching and Research (Study 1).

\begin{tabular}{|c|c|c|c|c|c|c|c|c|c|c|c|c|c|c|c|c|c|c|}
\hline & \multicolumn{4}{|c|}{ Teaching } & \multicolumn{4}{|c|}{ Research } & \multicolumn{10}{|c|}{ Correlations } \\
\hline & $M$ & $S D$ & $\omega_{\mathrm{h}}$ & Skew & $M$ & $S D$ & $\omega_{\mathrm{h}}$ & Skew & 1 & 2 & 3 & 4 & 5 & 6 & 7 & 8 & 9 & 10 \\
\hline \multicolumn{19}{|c|}{ Mastery goals } \\
\hline [1] Task approach & 7.2 & 1.0 & .85 & -1.9 & 7.3 & 0.8 & .71 & -1.8 & .54 & .37 & .64 & .41 & .44 & .27 & .29 & .26 & -.28 & .18 \\
\hline [2] Task avoidance & 6.8 & 1.3 & .83 & -1.4 & 6.7 & 1.4 & .82 & -1.4 & .45 & .82 & .32 & .50 & .42 & .67 & .29 & .56 & .01 & .24 \\
\hline [3] Learning approach & 6.8 & 1.2 & .88 & -1.3 & 7.2 & 0.9 & .80 & -1.9 & .60 & .30 & .59 & .56 & .31 & .20 & .20 & .21 & -.26 & .26 \\
\hline [4] Learning avoidance & 6.2 & 1.5 & .84 & -0.8 & 6.5 & 1.3 & .73 & -1.0 & .44 & .44 & .74 & .69 & .30 & .36 & .25 & .36 & -.09 & .20 \\
\hline \multicolumn{19}{|c|}{ Performance goals } \\
\hline [5] Appearance approach & 6.2 & 1.4 & .82 & -0.9 & 6.3 & 1.4 & .83 & -1.0 & .44 & .44 & .28 & .28 & .74 & .73 & .65 & .69 & .03 & .29 \\
\hline [6] Appearance avoidance & 6.4 & 1.5 & .86 & -1.1 & 6.3 & 1.6 & .85 & -1.1 & .32 & .66 & .16 & .24 & .79 & .78 & .52 & .76 & .11 & .29 \\
\hline [7] Normative approach & 4.7 & 1.8 & .92 & -0.3 & 4.8 & 1.7 & .86 & -0.4 & .31 & .28 & .20 & .23 & .63 & .51 & .70 & .69 & .10 & .22 \\
\hline [8] Normative avoidance & 5.6 & 1.8 & .89 & -0.6 & 5.6 & 1.7 & .83 & -0.6 & .31 & .54 & .20 & .28 & .68 & .74 & .71 & .74 & .10 & .28 \\
\hline \multicolumn{19}{|c|}{ Further goals } \\
\hline [9] Work avoidance & 2.8 & 1.7 & .95 & 0.7 & 2.1 & 1.3 & .87 & 1.4 & -.42 & -.08 & -.35 & -.24 & -.01 & .08 & .01 & .05 & .60 & .10 \\
\hline [10] Relational & 5.2 & 1.7 & .92 & -0.5 & 5.4 & 1.6 & .88 & -0.7 & .24 & .19 & .27 & .24 & .27 & .22 & .28 & .26 & -.07 & .56 \\
\hline
\end{tabular}

Note. $N=1151$. The whole theoretical range (1-8) was attained for all goal classes. Presented are bivariate manifest correlations within the goals for teaching (left triangular matrix) and within the goals for research (right triangular matrix) as well as between goals for teaching and their respective research related goal class (main diagonal, printed in bold). All $|r|>.03$ are statistically significant at $p<.05$. Latent correlations are provided in the electronic supplement.

\footnotetext{
${ }^{3}$ This estimator is robust to multivariate nonnormality and allows the inclusion of variables as indicators for latent factors that are characterized by a severe restriction of range (Flora \& Curran, 2004). Some of the achievement goal items were asymmetrically distributed, which poses a problem for estimators such as the maximum likelihood estimator that requires more evenly distributed functions (Rhemtulla, Brosseau-Liard, \& Savalei, 2012). To test the robustness of our findings irrespective of the estimator, we additionally ran all analyses with MLR as an estimator, which yielded overall similar estimations of the model parameters.
} (Muthén \& Muthén, 2017a). For structural equation iables were standardized by setting their means to 0 and variances to 1 . To evaluate the model fit, we used TLI as a relative fit index that also adjusts for parsimony, and RMSEA and CFI as noncentrality-based indices. used to assess the achievement goal classes, a certain amount of model misspecification is automatically invery good model fit indices are unlikely for complex models that simultaneously describe multiple goal clasvalues should be used to assess satisfactory model fit in such constellations (Fan \& Sivo, 2007). Thus, we Engel, Moosbrugger, and Müller (2003) and $\mathrm{Hu}$ and Bentler (1998) and used CFI > .90, TLI > .90, RMSEA plex models describing all ten goal classes, and CFI, TLI $\geq .95$ and RMSEA, SRMR $\leq .05$ for the other mod5.1.3.1 Measurement invariance across the teaching and the research domain. In order to confirm that the goal structure is independent across the teaching and the research domain, multi-group confirmatory factor 
analyses (MGCFA) were conducted. Using a step-up approach, we estimated a series of hierarchical models by imposing restrictions between the measurement models for the teaching and the research domain. We compared (a) a model in which the item-factor clusters were restricted to be equivalent for both groups (configural invariance), (b) a model in which the factor loadings were additionally restricted between these groups (metric invariance), (c) a model in which the item intercepts were additionally restricted (scalar invariance), and (d) a model in which the residual variances were additionally restricted (strict invariance). These models were specified following Muthén and Muthén (2017b). When a more restricted model does not describe the data worse than the previous, less restricted model, one can assume the corresponding form of invariance. As $\chi^{2}$ is overly sensitive to small, unimportant deviations in large samples (Chen, 2007; see Putnick \& Bornstein, 2016, for an overview) it has been suggested to use the cut-off value of $\triangle \mathrm{CFI}=.01$ paired with changes in RMSEA of .015 and SRMR of .030 (for metric invariance) or .015 (for scalar or residual invariance) for research scenarios as in the present study.

\subsubsection{Confirmatory factor analyses regarding the} separability of the teaching and the research domain. We used confirmatory factor analyses to test for each goal class separately, whether the corresponding items were described better by factors that distinguished between the teaching and the research domain than one factor. We compared these two models against each other using the $\chi^{2}$-test for difference testing provided by Mplus and additionally investigated differences in CFI and SRMR (for these analyses, we did not regard RMSEA as this fit index can be severely biased in models with little degree of freedom; see Kenny, Kaniskan, $\&$ McCoach, 2011). Besides these comparisons for the individual goal classes, we also estimated and compared two overall models containing all goal classes simultaneously - in the form of 20 factors (representing the ten goal classes for teaching and research each) or 10 factors (not distinguishing between the two domains).

\subsubsection{Correlations of goals between teaching and re-} search. We estimated manifest correlations as well as their confidence intervals to investigate and compare the domain specificity of the goals regarding teaching and research.

\subsubsection{Comparisons of means and standard deviations of goals between teaching and research. Similarly, we estimated the goals' means and standard deviations for the teaching and the research domain. Means were compared using paired $t$-tests, standard deviations us- ing likelihood-ratio (LR) tests of equality of variances.}

\subsection{Results and discussion}

\subsubsection{Preliminary analyses}

To confirm the core assumption of our research aims (being that the achievement goal framework works equally well for the teaching and the research domains), measurement invariance analyses were conducted by estimating a hierarchical series of multigroup models with increasing restrictions between both domains (see Table 2). The configural model described the data well and differences in model fit between the more restrictive models were small and below the used cut-off criteria (Chen, 2007); indeed they even satisfied the very conservative criterion proposed by Meade, Johnson, and Braddy (2008). As such, strict measurement in- variance can be assumed, implying that the same goal classes are being measured in the teaching and the research domain and that their means and standard deviations can adequately be compared to each other.

Table 2

Results of Measurement Invariance Testing (Study 1).

\begin{tabular}{lllll}
\hline & CFI & TLI & RMSEA & SRMR \\
\hline Configural invariance & .962 & .957 & .063 & .044 \\
Metric invariance & .963 & .959 & .062 & .044 \\
Scalar invariance & .963 & .965 & .057 & .045 \\
Strict invariance & .964 & .967 & .056 & .045 \\
\hline
\end{tabular}

Note. $N=1151$. 
Table 3

Results of Confirmatory Factor Analyses on the Separability of Achievement Goals Between Teaching and Research.

\begin{tabular}{|c|c|c|c|c|c|c|}
\hline & \multicolumn{3}{|c|}{ 1-factor model (domain-unspecific) } & \multicolumn{3}{|c|}{ 2-factor model (teaching, research) } \\
\hline & CFI & TLI & SRMR & CFI & TLI & SRMR \\
\hline \multicolumn{7}{|c|}{ Study 1} \\
\hline Task approach & .927 & .872 & .066 & .983 & .969 & .027 \\
\hline Task avoidance & .981 & .967 & .022 & .987 & .976 & .017 \\
\hline Learning approach & .941 & .896 & .051 & .993 & .988 & .014 \\
\hline Learning avoidance & .962 & .934 & .032 & .985 & .971 & .020 \\
\hline Appearance approach & .961 & .932 & .053 & .983 & .968 & .034 \\
\hline Appearance avoidance & .972 & .952 & .027 & .988 & .978 & .016 \\
\hline Normative approach & .953 & .918 & .062 & .990 & .982 & .022 \\
\hline Normative avoidance & .959 & .928 & .037 & .987 & .975 & .017 \\
\hline Work avoidance & .950 & .913 & .061 & .998 & .995 & .007 \\
\hline Relational goals & .912 & .847 & .083 & .993 & .987 & .016 \\
\hline \multicolumn{7}{|c|}{ Study 2} \\
\hline Task approach & .909 & .841 & .082 & .985 & .971 & .026 \\
\hline Task avoidance & .972 & .951 & .027 & .994 & .988 & .013 \\
\hline Learning approach & .935 & .887 & .098 & .996 & .993 & .016 \\
\hline Learning avoidance & .927 & .873 & .052 & .995 & .990 & .013 \\
\hline Appearance approach & .941 & .897 & .052 & .994 & .989 & .015 \\
\hline Appearance avoidance & .967 & .943 & .035 & .997 & .995 & .011 \\
\hline Normative approach & .968 & .943 & .063 & .999 & .999 & .007 \\
\hline Normative avoidance & .960 & .929 & .044 & .994 & .988 & .011 \\
\hline Work avoidance & .894 & .814 & .115 & .998 & .997 & .013 \\
\hline Relational goals & .959 & .929 & .096 & .999 & .998 & .007 \\
\hline
\end{tabular}

Note. $N($ Study 1$)=1151, N($ Study 2$)=771$. Presented are the fits of two models for each goal class (one factor vs. two factors distinguishing between teaching and research).

\subsubsection{Separability of achievement goals between teach- ing and research}

To confirm the separability of achievement goals between the teaching and the research domain, we estimated two models for each goal classes (a one factor solution vs. a two factor solution distinguishing between teaching and research; Table 3). Our results indicated that all two-factor models described the data well and significantly better than the one-factor solutions (all $\chi^{2}$-difference tests were statistically significant: $\left.\Delta \chi^{2}>107, d f=1, p<.001\right)$. Opposed to this, the one-factor models did not describe the data well enough - with the exception of task avoidance and appearance avoidance goals that were also well described by models that did not distinguish between the goals' focus on teaching or research. These findings were additionally reflected on the overall level, where we found that a 20 factor model (that distinguished all goal classes for teaching and research separately) described the data well and significantly better than a model in which the ten goals were not distinguished by domain $(\mathrm{CFI}=.954, \mathrm{TLI}=.949, \mathrm{RMSEA}=.046, \mathrm{SRMR}=$ $.046 ; \mathrm{CFI}=.928, \mathrm{TLI}=.925, \mathrm{RMSEA}=.056, \mathrm{SRMR}$ $=.065)$. Taken together, this confirms our hypothesis that achievement goals can be well distinguished between the teaching and the research domains (Hypothesis H1).

\subsubsection{Associations of achievement goals between teach- ing and research}

Based on their separability, we investigated the correlations for each goal class between the teaching and the research domain (diagonal in Table 1). As expected, we found moderate to strong correlations that reflected a substantial amount of shared variance in goal striving between both domains (ranging between 29-67\%). Fig. 1 shows the correlation coefficients and their $95 \%$-confidence intervals for the ten goal classes. As can be inferred from the non-overlapping confidence intervals, performance goals and mastery avoidance goals were more strongly correlated between teaching and research than mastery approach, work-avoidance and relational goals. This largely affirms our expectations (H2). Performance avoidance goals had descriptively, but not statistically significantly, stronger correlations than performance approach goals.

\subsubsection{Comparisons of means and standard deviations of achievement goals between teaching and research}

Subsequently, we investigated differences in goal pursuit between both domains. Differences in means and standard deviations between teaching and research are presented in Table 4 . In line with our expectations (H3), they indicated that learning approach goals were 


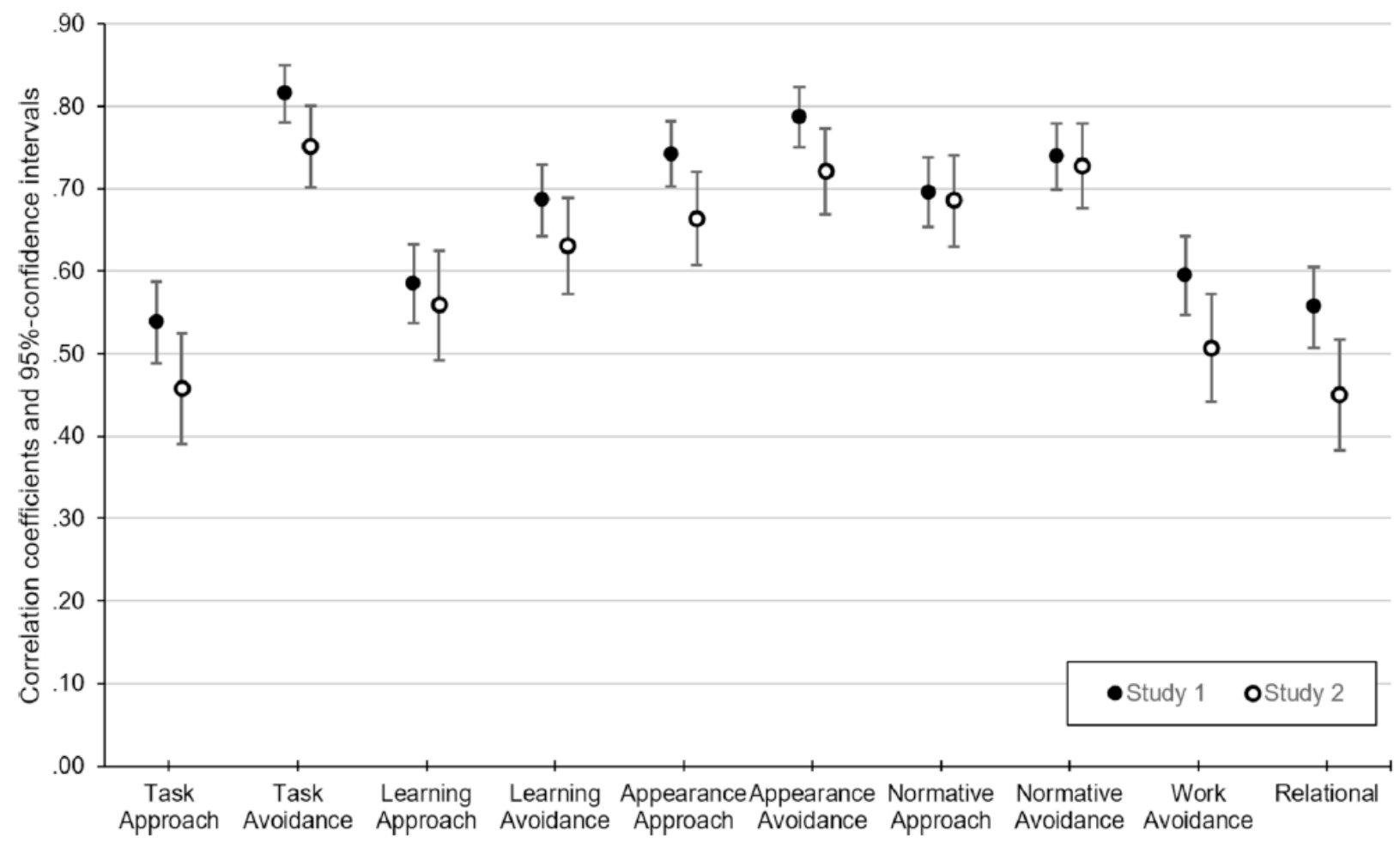

Fig. 1. Correlation coefficients and their 95\%-confidence intervals of the ten goals reflecting their association between the teaching and the research domain.

pursued to a greater extent in the research than in the teaching domain. Opposed to that, work-avoidance goals were reported more strongly for teaching than for research. Besides these medium mean differences, we also observed small differences for learning avoidance and relational goals that were both more strongly pursued in the research than in the teaching domain, while the other mean differences were not practically relevant due to their small effect sizes $(d \leq .10) .{ }^{4}$ Regarding the standard deviations, we found substantially more vari-

Table 4

Comparisons of Means and Standard Deviations Between Teaching and Research.

\begin{tabular}{|c|c|c|c|c|c|c|c|c|c|c|c|c|c|c|}
\hline & \multicolumn{8}{|c|}{ Differences in means } & \multicolumn{6}{|c|}{ Differences in standard deviations } \\
\hline & \multicolumn{4}{|c|}{ Study 1} & \multicolumn{4}{|c|}{ Study 2} & \multicolumn{3}{|c|}{ Study 1} & \multicolumn{3}{|c|}{ Study 2} \\
\hline & $\Delta M$ & $t$ & $p$ & $d$ & $\Delta M$ & $t$ & $p$ & $d$ & $\Delta S D$ & $\chi^{2}$ & $p$ & $\Delta S D$ & $\chi^{2}$ & $p$ \\
\hline \multicolumn{15}{|c|}{ Mastery goals } \\
\hline Task approach & -0.09 & -3.53 & $<.001$ & -0.10 & -0.21 & -5.16 & $<.001$ & -0.20 & 0.17 & 60.14 & $<.001$ & 0.14 & 19.67 & $<.001$ \\
\hline Task avoidance & 0.07 & 3.14 & .002 & 0.09 & 0.01 & 0.20 & .840 & 0.01 & -0.09 & 5.50 & .009 & 0.03 & 0.11 & .368 \\
\hline Learning approach & 0.43 & 14.48 & $<.001$ & 0.44 & 0.63 & 14.01 & $<.001$ & 0.54 & 0.31 & 162.68 & $<.001$ & 0.29 & 61.74 & $<.001$ \\
\hline Learning avoidance & 0.26 & 7.68 & $<.001$ & 0.23 & 0.57 & 11.14 & $<.001$ & 0.43 & 0.13 & 23.65 & $<.001$ & 0.19 & 17.94 & $<.001$ \\
\hline \multicolumn{15}{|c|}{ Performance goals } \\
\hline Appearance approach & 0.07 & 2.38 & .018 & 0.08 & 0.20 & 4.27 & $<.001$ & 0.16 & 0.01 & 0.87 & .175 & 0.07 & 4.24 & .020 \\
\hline Appearance avoidance & -0.07 & -2.44 & .015 & -0.07 & 0.11 & 2.38 & .017 & 0.09 & -0.09 & 4.81 & .014 & 0.06 & 2.30 & .064 \\
\hline Normative approach & 0.11 & 2.60 & .010 & 0.08 & 0.28 & 4.81 & $<.001$ & 0.19 & 0.10 & 7.60 & .002 & 0.10 & 3.43 & .031 \\
\hline Normative avoidance & 0.08 & 2.03 & .043 & 0.06 & 0.10 & 1.86 & .063 & 0.07 & 0.11 & 11.33 & $<.001$ & 0.07 & 2.82 & .046 \\
\hline \multicolumn{15}{|c|}{ Further goals } \\
\hline Work avoidance & -0.69 & -16.78 & $<.001$ & -0.50 & -0.73 & -12.61 & $<.001$ & -0.49 & 0.41 & 138.81 & $<.001$ & 0.38 & 72.01 & $<.001$ \\
\hline Relational & 0.22 & 4.75 & $<.001$ & 0.14 & 0.55 & 8.19 & $<.001$ & 0.31 & 0.07 & 3.17 & .037 & 0.00 & 0.02 & .433 \\
\hline
\end{tabular}

Note. $N($ Study 1$)=1151, N($ Study 2$)=771 . \Delta=$ research - teaching .

${ }^{4}$ On the multivariate level, a MANOVA with all 10 goal classes as dependent variables and domain as a factor revealed the same differences (Wilks $\lambda=.693$; multivariate $F(10,1084)=47.9 ; p<.001 ; \eta^{2}=.31$ ). 
Table 5

Descriptive Statistics and Correlations for the Achievement Goals for Teaching and Research (Study 2).

\begin{tabular}{|c|c|c|c|c|c|c|c|c|c|c|c|c|c|c|c|c|c|c|}
\hline & \multicolumn{4}{|c|}{ Teaching } & \multicolumn{4}{|c|}{ Research } & \multicolumn{10}{|c|}{ Correlations } \\
\hline & $M$ & $S D$ & $\omega_{\mathrm{h}}$ & Skew & $M$ & $S D$ & $\omega_{\mathrm{h}}$ & Skew & 1 & 2 & 3 & 4 & 5 & 6 & 7 & 8 & 9 & 10 \\
\hline \multicolumn{19}{|c|}{ Mastery goals } \\
\hline [1] Task approach & 7.0 & 1.3 & .80 & -2.8 & 7.1 & 1.1 & .76 & -2.9 & .45 & .42 & .73 & .52 & .58 & .41 & .39 & .43 & -.18 & .34 \\
\hline [2] Task avoidance & 6.3 & 1.8 & .84 & -1.5 & 6.4 & 1.8 & .80 & -1.5 & .48 & .75 & .37 & .49 & .42 & .62 & .28 & .55 & .09 & .29 \\
\hline [3] Learning approach & 6.6 & 1.4 & .84 & -1.8 & 7.2 & 1.1 & .91 & -2.5 & .76 & .40 & .47 & .66 & .49 & .40 & .32 & .39 & -.19 & .37 \\
\hline [4] Learning avoidance & 6.0 & 1.7 & .83 & -1.2 & 6.5 & 1.6 & .76 & -1.6 & .59 & .51 & .72 & .63 & .43 & .48 & .30 & .43 & -.05 & .32 \\
\hline \multicolumn{19}{|c|}{ Performance goals } \\
\hline [5] Appearance approach & 5.9 & 1.6 & .83 & -1.3 & 6.1 & 1.5 & .82 & -1.3 & .60 & .49 & .49 & .48 & .66 & .73 & .68 & .71 & .03 & .43 \\
\hline [6] Appearance avoidance & 6.0 & 1.8 & .86 & -1.3 & 6.2 & 1.7 & .86 & -1.3 & 47 & .65 & .38 & .47 & .79 & .73 & .52 & .77 & .10 & .35 \\
\hline [7] Normative approach & 4.5 & 2.0 & .92 & -0.3 & 4.8 & 1.9 & .90 & -0.4 & .37 & .35 & .34 & .37 & .68 & .58 & .69 & .68 & .12 & .30 \\
\hline [8] Normative avoidance & 5.4 & 2.0 & .90 & -0.8 & 5.5 & 1.9 & .87 & -0.7 & .43 & .62 & .38 & .48 & .72 & .79 & .70 & .73 & .09 & .35 \\
\hline \multicolumn{19}{|c|}{ Further goals } \\
\hline [9] Work avoidance & 2.7 & 1.7 & .93 & 0.9 & 2.0 & 1.3 & .90 & 1.6 & -.13 & .14 & -.16 & -.04 & .19 & .25 & .16 & .20 & .51 & .11 \\
\hline [10] Relational & 4.9 & 1.7 & .87 & -0.5 & 5.4 & 1.7 & .87 & -0.7 & .42 & .23 & .41 & .34 & .39 & .28 & .34 & .31 & .02 & .44 \\
\hline
\end{tabular}

Note. $N=771$. The whole theoretical range (1-8) was attained for all goal classes. Presented are bivariate manifest correlations within the goals for teaching (left triangular matrix) and within the goals for research (right triangular matrix) as well as between goals for teaching and their respective research related goal class (main diagonal, printed in bold). All $|r|>.05$ are statistically significant at $p<.05$. Latent correlations are provided in the electronic supplement.

ance in the teaching domain than in the research domain. This was especially the case for task approach, learning approach, and work-avoidance goals.

Taken together, these findings from Study 1 confirm the measurement invariance of goals between teaching and research - a main assumption of the current research - and provide a good understanding of their domain specificity by presenting clear evidence regarding goal separability, their associations, and differences in goal pursuit between teaching and research (supporting hypotheses H1, H2, and H3). In Study 2, we replicated these findings, and based on them, investigated the goal congruence between both domains and its relevance for

scholars' work stress, job satisfaction, and perceptions of the teaching-research nexus (H4).

\section{Study 2}

\subsection{Method}

\subsubsection{Procedure and sample}

771 university scholars $(45.5 \%$ full professors, $24.9 \%$ academic staff with $\mathrm{PhD}, 29.6 \%$ academic staff without $\mathrm{PhD}$; males: $53.1 \%$, females: $46.9 \%$; mean age: 38.7 years; from thirteen different subjects) from 71 public German universities participated in the study.

\subsubsection{Measurements}

Besides participants' achievement goals for teaching and research, their work stress, job satisfaction, and subjective perceptions of the teaching-research nexus, we also assessed their time spent on teaching and on research (both in hours, average per week) as well as their academic status (full professor, academic staff with $\mathrm{PhD}$, or academic staff without $\mathrm{PhD}$ ) and gender as background variables.

\subsubsection{Achievement goals for teaching and research.} We measured participants' achievement goals for teaching and research using the same scale as in Study 1. Like before, the internal reliabilities were very satisfying (see Table 5).

6.1.2.2 Work stress. We used the German version of the MBI for general professions (MBI-GS-D; Büssing \& Glaser, 1999), which we slightly modified to accommodate for the academic context. As subscales of work stress, it distinguishes (a) emotional exhaustion (e.g., "I feel emotionally exhausted by my work"; 6 items; $\omega_{\mathrm{h}}=$ .84), (b) cynicism (e.g., "I just want to do my job and be left alone"; 5 items; $\omega_{\mathrm{h}}=.76$ ), and (c) reduced personal accomplishment (e.g., "I feel good when I have achieved something at work" $; 5$ items; $\omega_{\mathrm{h}}=.75$ ). The respondents were requested to refer in their answers to their current work and to indicate on an 8-point Likert-

\footnotetext{
${ }^{5}$ The items of the last subscale have negative polarization and were reversed for the analyses; therefore, high values represent a strongly perceived lack of personal accomplishment.
} 
type scale ranging from 1 (never) to 8 (very often) how often they had experienced the presented aspects of work stress within the past 6 months.

6.1.2.3 Job satisfaction. To assess the participants' satisfaction with their job, we adapted a scale by van Dick, Schnitger, Schwartzmann-Buchelt, and Wagner (2001) for both work domains. With three items (one of which being reverse scored), participants were asked to what extent they were satisfied with their job in the teaching domain (e.g., "Generally speaking, I am very satisfied with the teaching-related aspects of my job"; $\omega_{\mathrm{h}}=.82$ ) and in the research domain (e.g., "Generally speaking, I am very satisfied with the research-related aspects of my job"; $\left.\omega_{\mathrm{h}}=.85\right) .{ }^{6}$ All items were answered on Likerttype scales ranging from 1 (do not agree at all) to 8 (agree completely).

\subsubsection{Subjective perceptions of the teaching-research} nexus. To assess the participants' subjective perceptions of the teaching-research nexus, we used a scale by Daumiller and Dresel (2018). This scale distinguishes four aspects of the integration and synergy of both domains: research is part of teaching (e.g., "Research also has a place in teaching"; 3 items; $\omega_{\mathrm{h}}=.92$ ), teaching is part of research (e.g., "Teaching also has a place in research"; 3 items; $\omega_{\mathrm{h}}=.92$ ), research enriches teaching (e.g., "Being active in research contributes to good teaching"; 3 items; $\omega_{\mathrm{h}}=.88$ ), and teaching enriches research (e.g., "Being active in teaching contributes to good research"; 3 items; $\left.\omega_{\mathrm{h}}=.94\right)$. The participants were asked to state how much they agreed with these basic statements on the relationship between research and teaching in their subject in general using a Likerttype scale ranging from 1 (not true at all) to 8 (completely true).

\subsubsection{Analyses}

To test the robustness of our findings, we first repeated all analyses from Study 1 regarding the goals' separability, associations, and mean and variance differences between teaching and research. For the remaining research questions, we then investigated the goal congruence between both domains and its associations. Unless otherwise noted, all statistical analyses and specifications are the same as in Study 1.
To model the goal congruence between teaching and research, we calculated intraindividual correlations between the different pairs of goal classes between teaching and research. This procedure yields a correlation score for each participant that represents the extent to which this person pursues the ten achievement goals similarly in the teaching domain and the research domain. This score was subsequently correlated with work stress, job satisfaction, and subjective perceptions of the teaching-research nexus as well as the assessed background variables.

\subsection{Results and discussion}

\subsubsection{Replication of findings from Study 1}

In a first step, we ran the same analyses as in Study 1 to test the robustness of the previous findings. As in Study 1, we observed that the goal classes were described statistically significantly better when distinguishing by their focus on teaching and research (Table 5), also for a 20 -factor and a 10-factor model (CFI = .962 , TLI $=.958$, RMSEA $=.038$, SRMR $=.046$, and $\mathrm{CFI}=.908, \mathrm{TLI}=.903, \mathrm{RMSEA}=.058, \mathrm{SRMR}=$ .084). At the same time, there were substantial correlations between the domains that were very similar to those found in Study 1 (see Fig. 1). Likewise, we found very similar mean level differences (see Table 4). These were, on average, more pronounced than in Study 1, particularly regarding learning avoidance and relational goals that were more strongly pursued for research than for teaching. Besides this, we also observed small differences in task approach and performance approach goals. Additionally, regarding the extent of interindividual differences of goal striving, we observed a similar pattern as in the previous study, with goal striving in the teaching domain exhibiting greater variability than in the research domain and the strongest differences for mastery approach and work-avoidance goals. Taken together, the replicability of our findings strongly affirms the validity of our results.

\subsubsection{Goal congruence and its associations with work stress, job satisfaction, and perceptions of the teaching- research nexus}

We measured the goal congruence between teaching and research by calculating intraindividual correlations for each participant. This measure indicated, in

\footnotetext{
${ }^{6}$ Confirmatory factor analyses indicated that job satisfaction in the teaching domain was clearly distinguishable from job satisfaction in the research domain, while both aspects were only little associated with each other $(r=.29, p<.001)$.
} 
Table 6

Descriptive Statistics and Correlations for Goal Congruence with Other Variables (Study 2).

\begin{tabular}{|c|c|c|c|c|c|c|c|}
\hline & \multicolumn{5}{|c|}{ Descriptive statistics } & \multicolumn{2}{|c|}{$\begin{array}{l}\text { Correlation with goal } \\
\text { congruence }\end{array}$} \\
\hline & $M$ & $S D$ & Min & Max & Skew & $r$ & $p$ \\
\hline Goal congruence & .77 & .25 & -.65 & 1.00 & -2.14 & & \\
\hline \multicolumn{8}{|c|}{ Work stress } \\
\hline Emotional exhaustion & 3.20 & 1.65 & 1.00 & 8.00 & 0.68 & -.15 & $<.001$ \\
\hline Cynicism & 2.91 & 1.57 & 1.00 & 8.00 & 1.02 & -.22 & $<.001$ \\
\hline Reduced personal accomplishments & 2.64 & 1.03 & 1.00 & 7.20 & 0.87 & -.20 & $<.001$ \\
\hline \multicolumn{8}{|c|}{ Job satisfaction } \\
\hline With teaching & 6.33 & 1.36 & 1.00 & 8.00 & -1.18 & .24 & $<.001$ \\
\hline With research & 5.97 & 1.60 & 1.00 & 8.00 & 0.80 & .07 & .078 \\
\hline \multicolumn{8}{|c|}{ Perceptions of the teaching-research nexus } \\
\hline Research is part of teaching & 6.02 & 1.74 & 1.00 & 8.00 & -0.83 & .20 & $<.001$ \\
\hline Teaching is part of research & 4.65 & 2.08 & 1.00 & 8.00 & -0.03 & .19 & $<.001$ \\
\hline Research enriches teaching & 6.49 & 1.50 & 1.00 & 8.00 & -1.22 & .23 & $<.001$ \\
\hline Teaching enriches research & 4.80 & 2.07 & 1.00 & 8.00 & -0.10 & .19 & $<.001$ \\
\hline \multicolumn{8}{|c|}{ Background variables } \\
\hline Teaching time & 15.6 & 11.8 & 1 & 188 & 5.72 & .12 & .003 \\
\hline Research time & 23.4 & 13.0 & 1 & 70 & 0.45 & -.13 & .001 \\
\hline Full professor $(1=$ yes, $0=$ no $)$ & .46 & .42 & 0 & 1 & 0.62 & .11 & .004 \\
\hline $\operatorname{PhD}(1=$ yes, $0=$ no $)$ & .25 & .37 & 0 & 1 & 1.56 & .06 & .138 \\
\hline Gender $(1=$ female, $0=$ male $)$ & .47 & .50 & 0 & 1 & 0.12 & .05 & .219 \\
\hline
\end{tabular}

Note. $N=771$.

line with the previous findings, that, on average, participants prioritized their goals in both domains in a rather similar manner (reflected in the high mean of the goal congruence, i.e., the average intraindividual correlation, of $.77, S D=.25$, see Table 6 ).

Besides this, its standard deviation was significantly different than zero (95\%-confidence interval: [.23; .26]), indicating substantial differences between the respondents in their goal congruence. This variance in turn, was significantly associated with the participants' answers to the other measures (for which we found small to medium correlations): The more the participants' goals in the domains of teaching and research were congruent (i.e., the more they prioritized the same goal classes in both domains), the more they were also convinced of a high integration and synergy between teaching and research. Also, strong goal congruence went along with decreased work-stress and increased job satisfaction for the teaching domain. Lastly, goal congruence was higher for full professors than for other academic staff and positively associated with the time spent teaching, and negatively with the time spent on research. Subsequent stepwise regression analyses with backwards elimination indicated that all associations remained robust when simultaneously examining all variables in a single model, with the exception of work stress (for which only the subscale of cynicism remained statistically significant) and subjective perceptions of the teaching-research nexus (for which only the subscales "teaching as a part of research" and "research enriches teaching" remained statistically significant). In line with our expectations, this points to the importance of congruent goals for well-being and its association with subjective perceptions of the teachingresearch nexus.

\section{General discussion}

The present study built on university scholars' achievement goals mattering for teaching and research, the core tasks of university faculty, however little has been known about their domain specificity. To this end, we investigated the separability, associations, and differences, as well as the interplay of their motivations between these two domains by conducting two empirical studies with German university scholars. Strengths of our investigation include the two-study design with which we replicated the main findings, the large and representative samples, the fine grained assessment of goals that was symmetrical for both domains, and the confirmation of measurement invariance across the domains. Our results endorse that achievement goals can be separated between teaching and research, while sharing a significant portion of common variance and being differently pursued (more adaptive goals for research, more variability in goals for teaching). Individ- 
uals differed in their goal congruence which was associated with work stress, job satisfaction, and beliefs about the teaching-research-nexus.

Regarding the separability of scholars' achievement goals, we found, in line with our expectations, that the motivations in these domains were described substantially better when distinguishing between teaching and research - in fact, with the exception of task avoidance goals, the data could only be well described when distinguishing between the two domains (confirmation of Hypothesis H1). This attests to an important foundation for research on university faculty: Their motivationin the form of their achievement goals - should be conceptualized and assessed in a domain-specific manner. As such, this finding strongly supports and justifies the approaches used in existing research that domain-specifically investigated scholars' achievement goal striving in the teaching domain (Daumiller et al., 2019; Daumiller et al., 2015; Daumiller et al., 2016) or the research domain (Daumiller \& Dresel, 2020; Janke et al., 2018). Also, this finding goes beyond previous AGT based investigations, indicating that the motivations of university faculty might generally better be construed domain-specifically. This expands the findings by Bailey (1999) on the domain-specificity of selfefficacy beliefs (which are, already by definition and operationalization much different between teaching and research). Opposed to this, achievement goals (including their measurement in the current work) are rather similar for both domains. As such, our findings on their separability act as strong argumentation for different motivational processes that might therefore also be expected for other motivational constructs (e.g., task value, need satisfaction).

Based on the separability of the goals between both domains, we subsequently investigated their associations. Each achievement goal class containing a substantial fraction of common variance between the domains (26-67\%) and also a substantial amount of domain-specific variance, confirmed our expectations and a basic tenet of contemporary AGT: These findings attest that preferences for achievement goals have partly global and partly domain-specific components and that different achievement environments, such as teaching and research, go along with different goal endorsement (Bong, 2001, 2004; Fryer \& Elliot, 2007; Sparfeldt et al., 2015; Sparfeldt et al., 2007). Additionally, our specific expectations regarding different levels of specificity for the different goal classes were fulfilled (confirmation of $\mathrm{H} 2$ ), indicating a higher domain-specificity for approach based goals opposed to avoidance based goals as well as mastery goals opposed to performance goals. Actually, descriptively we even found very similar correlation coefficients to Bong (2004), Sparfeldt et al. (2015), and Sparfeldt et al. (2007). As far as we are aware, the current work was the first to investigate the domain specificity of achievement goals in a nonstudent context. Therefore, our results strongly support the generalizability of findings on achievement goal specificity across different achievement contexts and makes it probable that general factors lie behind the different levels of specificity observed for the different achievement goals (avoidance goals containing more personality-stable fractions, learning opportunities being more context dependent than to make a good impression and outperform others). It is noteworthy that we also found work avoidance and relational goals to exhibit a similar level of specificity as mastery approach goals. Like mastery goals, they likely substantially depend on domain-dependent aspects, such as the subjective importance of the respective domain and the therein involved people. Aside these different levels of specificity, the average association that we found for goals for teaching and goals for research supports our assumption that there are at least partly similar motivations for teaching and research (which may be both a function of their personality as well as the overall context, e.g., the institutional embeddedness), while at the same time there are also substantial differences for their motivations, especially regarding mastery approach, work avoidance goals, and relational goals. As such, just like teaching and research itself, scholars' individual motivations are also intertwined between these two domains.

The domain-specificity of faculty motivations was also indicated by the differences in the means and variances of the different goals between the two domains. The on average stronger mastery based, stronger relational, and fewer work avoidance goals in the research than the teaching domain imply that generally scholars have a more adaptive motivation for research than for teaching. This might be explained by (a) scholars often valuing research more than teaching (e.g., Marsh \& Hattie, 2002; Smeby, 1998), (b) scholars mainly beginning their career with a strong motivation for research, or (c) because those with a strongly adaptive motivation for research are more likely to stay within the university system (while the motivations for teaching are not as decisive a factor to this end). Finally, these differences are in line with contemporary incentive structures in the university systems, where, including in Germany, research is often valued more strongly than teaching (Backes-Gellner \& Schlinghoff, 2010; Leisyte 
et al., 2009). At the same time, our expectations regarding more variability in the goal pursuit in the teaching than in the research domain were also fulfilled (confirmation of H3). Interestingly, we found these differences in variability mainly due to mastery approach and work avoidance goals. Specifically, the scholars we investigated pursued these types of goals to a more similar extent in the research than in the teaching context and also to a more similar extent than the other goal classes. This reduced variability might be attributed to the functionality of these goals being most explicit and clear and the research process itself requiring strong mastery approach and low work avoidance goals and does not work well for much different emphases on these goals.

Lastly, regarding the interplay of the goals for teaching and for research, we found the extent to which similar goals were prioritized in both domains, i.e., goal congruence, to be a meaningful variable describing the overall combination of motivations for teaching and motivations for research (confirmation of $\mathrm{H} 4$ ). Our findings attest that previous theorizing and models of how goals align with a person's interests and core values (e.g., Gorges et al., 2014; Sheldon \& Elliot, 1999) can also be transferred to the level of a person's goals between different domains. Here, goal congruence and its functionality can be attributed to the alignment of the goals between the domains itself (and how they align/conflict with each other in the goal striving process), and to their alignment with implicit motives or other aspects rooted within the personality of the individual. While we consider goal congruence an interesting variable in the context of exploring and investigating the domain specificity of achievement goals and their interplay, we believe that primarily and chiefly the individual achievement goal classes are relevant for instructors' behaviors (e.g., learning behaviors, achievement). Also, for the interpretation of this variable, it needs to be borne in mind that goals might be pursued in a maladaptive way, but similarly so, in both domains, which would still reflect high goal congruence. As such, goal congruence appears chiefly relevant in research contexts as in the present study, relevant for specific aspects of instructors' experiences and cognition, like the ones we investigated. Here, the associations that we found for work stress and job satisfaction likely reflect experienced goal conflicts and cognitive dissonance that are known to negatively impair well-being at work (Boudreaux \& Ozer, 2013; Festinger, 1962). To explain this, both of the two above described perspectives may be considered: Prioritizing different goals in the teaching and in the research domain, (a) may trigger goal conflicts in achievement situations that are relevant for both domains (and likely also when frequently switching between both domains), and (b) makes it more unlikely that all goals align well with deeper personality aspects while confronting the individual with different sets of values (in the form of prioritized goals) for both domains, which can lead to cognitive dissonance. Beside this, based on our findings, also the subjective perceptions of the teaching-research nexus can be considered relevant for how similar goals are prioritized and might also mirror whether one domain is prioritized over another (e.g., Bak, 2015). Regarding these associations, both causal directions are possible: strong goal congruence could facilitate experiencing that both domains can align well and function synergistically, or believing in high integration and synergy could lead to scholars pursuing more similar goals (an analogous argument can be made for work stress). As such, it would be very interesting to follow up on goal congruence and its causal embeddedness with longitudinal research designs. Beyond that, an interesting research direction entails including the extent to which scholars prefer one domain over another and in how far this preference matches with their everyday work (see Stupnisky, Weaver-Hightower, \& Kartoshkina, 2015; Stupnisky et al., 2017) - as this might be relevant for their satisfaction with teaching-research balance and their goal striving processes in both domains.

Further research directions pertain to other areas of university scholars' work, such as administration or specific aspects like mentoring (Morales, Grineski, \& Collins, 2017). While administration is indeed quite time intensive and can be regarded as a third relevant group of university scholars' tasks (see Janke \& Dickhäuser, 2018, for a similar argument), it typically need not constitute a real achievement context (although some scholars may perceive it as such). Opposed to that, aspects such as mentoring are very particular and do not apply for all university scholars; consequently, we do not consider them chiefly relevant for investigations into the domain specificity of university scholars' achievement goals. However, it would be very interesting to include subdomains (e.g., in the teaching domain: different courses taught by an instructor) to facilitate a comprehensive understanding of the domain specificity of achievement goals and their malleability.

When interpreting the presented findings, two main limitations should be born in mind. First, only German university instructors were investigated. While it is unlikely that this affected the findings on separability and associations, the differences in general goal striving may in part be affected by the general valuation of 
teaching and research (e.g., teaching might be valued more in the US than in Germany) and cultural influences thereupon (Markus \& Kitayama, 1991). Second, it may also be possible that some measures might be partly affected by social desirability (e.g., work avoidance goals). In consequence, the absolute means of the goals should carefully be interpreted.

Aside from the above described implications for theory (AGT as well as motivation of university scholars), the present work has substantial implications for future research and practical interventions. Our findings advise that when investigating motivations in the form of achievement goals of university scholars, teaching and research should be distinguished, both conceptually and empirically. Besides this, our findings can be taken as indication that practical interventions focused on fostering and supporting adaptive goal striving processes should be both domain specific as well as global (to acknowledge the impact that an achievement domain has for goal pursuit therein, as well as the domain-unspecific components of achievement goal striving).

Taken together, our study helps to understand the domain specificity of faculty motivation and the separability, associations, and differences between achievement goals for the teaching and the research domain as well as their congruence between both domains, which is important for theorizing about faculty motivation and in gaining an adequate assessment and fostering of achievement goals.

\section{References}

Backes-Gellner, U., \& Schlinghoff, A. (2010). Career incentives and "publish or perish" in German and U.S. Universities. European Education, 4, 26-52. https://doi.org/ 10.2753/eue1056-4934420302.

Bailey, J. G. (1999). Academics' motivation and self-efficacy for teaching and research. Higher Education Research \& Development, 18, 343-359. https://doi.org/10.1080/0729436990180305.

Bak, H. J. (2015). Too much emphasis on research? An empirical examination of the relationship between research and teaching in multitasking environments. Research in Higher Education, 56, 843-860. https://doi.org/10.1007/s11162-015-9372-0.

Bardach, L., Yanagida, T., Schober, B., \& Lüftenegger, M. (2018). Within-class consensus on classroom goal structures - Relations to achievement and achievement goals in mathematics and language classes. Learning and Individual Differences, 67, 78-90. https://doi.org/10.1016/j.lindif.2018.07.002.
Bong, M. (2001). Between-and within-domain relations of academic motivation among middle and high school students. Journal of Educational Psychology, 93, 23-34. https://doi.org/10.1037//0022-0663.93.1.23.

Bong, M. (2004). Academic motivation in self-efficacy, task value, achievement goal orientations, and attributional beliefs. The Journal of Educational Research, 97, 287-298. https://doi.org/10.3200/joer.97.6.287-298.

Boudreaux, M. J., \& Ozer, D. J. (2013). Goal conflict, goal striving, and psychological well-being. Motivation and Emotion, 37, 433-443. https://doi.org/10.1007/ s11031012-9333-2.

Brophy, J. (2005). Goal theorists should move on from performance goals. Educational Psychologist, 40, 167-176. https://doi.org/10.1207/s15326985ep4003_3. Brown, T. A. (2014). Confirmatory factor analysis for applied research. Guilford Publications.

Büssing, A., \& Glaser, J. (1999). German version of the maslach burnout inventory - General survey (MBI-GS$D)$. Munich, Germany: Technical University, Department of Psychology.

Butler, R., \& Shibaz, L. (2008). Achievement goals for teaching as predictors of students' perceptions of instructional practices and students' help seeking and cheating. Learning and Instruction, 18, 453-467. https://doi.org/10.1016/j.learninstruc.2008.06.004.

Butler, R. (2012). Striving to connect: Extending an achievement goal approach to teacher motivation to include relational goals for teaching. Journal of Educational Psychology, 104, 726-742. https://doi.org/10.1037/a0028613.

Chen, F. (2007). Sensitivity of goodness of fit indexes to lack of measurement invariance. Structural Equation Modeling, 14, 464-504. https://doi.org/10.1080/ 10705510701301834.

Coate, K., Barnett, R., \& Williams, G. (2001). Relationships between teaching and research in higher education in England. Higher Education Quarterly, 55, 158-174. https://doi.org/10.1111/1468-2273.00180.

Daumiller, M., \& Dresel, M. (2018). Subjective perceptions of the teaching-research nexus and occupational stress at universities. Zeitschrift für Entwicklungspsychologie und Pädagogische Psychologie/Journal of Developmental and Educational Psychology, 50, 126-138. https://doi.org/10.31234/osf.io/a96ph.

Daumiller, M., \& Dresel, M. (2020). Researchers' achievement goals, work stress, and professional development: Results of three studies. Contemporary Educational Psychologyhttps://doi.org/10.1016/j.cedpsych.2020.101843 Advance online publication.

Daumiller, M., Figas, P., \& Dresel, M. (2015). Selbstbezogene Ziele von Dozierenden: Ergebnisse einer Interviewstudie [Self-referred goals of university lecturers: Results from an interview study]. Beiträge zur Hochschulforschung/Contributions to University Research, 4, 
52-64. Retrieved from http://www.bzh.bayern.de/uploads/media/4-2015- Daumiller-Figas-Dresel.pdf.

Daumiller, M., Grassinger, R., Dickhäuser, O., \& Dresel, M. (2016). Structure and relationships of university instructors' achievement goals. Frontiers in Psychology, 7. https://doi.org/10.3389/fpsyg.2016.00375.

Daumiller, M., Dickhäuser, O., \& Dresel, M. (2019). University instructors' achievement goals for teaching. Journal of Educational Psychology, 111, 131-148. https:// doi.org/10.1037/edu0000271.

Daumiller, M., Stupnisky, S., \& Janke, S. (2020). Motivation of higher education faculty: Theoretical approaches, empirical evidence, and future directions [Editorial]. International Journal of Educational Research, 20https://doi.org/10.1016/j.ijer.2019.101502.

Dweck, C. S. (1986). Motivational processes affecting learning. The American Psychologist, 41, 1040-1048. https://doi.org/10.1037//0003-066x.41.10.1040. Dweck, C. S., \& Leggett, E. L. (1988). A social-cognitive approach to motivation and personality. Psychological Review, 95, 256-273. https://doi.org/10.1037//0033295x.95.2.256.

Elliot, A. (1999). Approach and avoidance motivation and achievement goals. Educational Psychologist, 34, 169189. https://doi.org/10.1207/s15326985ep3403_3. Elliot, A. (2005). A conceptual history of the achievement goal construct. In A. Elliot, \& C. Dweck (Eds.). Handbook of competence and motivation (pp. 52-72). New York, NY: Guildford.

Elliot, A., \& Harackiewicz, J. M. (1996). Approach and avoidance achievement goals and intrinsic motivation: A mediational analysis. Journal of Personality and Social Psychology, 70, 461-475. https://doi.org/10.1037//0022-3514.70.3.461.

Elliot, A., \& McGregor, H. A. (2001). A $2 \times 2$ achievement goal framework. Journal of Personality and Social Psychology, 80, 501-519. https://doi.org/10.1037/00223514.80.3.501.

Elliot, A., Murayama, K., \& Pekrun, R. (2011). A 3 x 2 achievement goal model. Journal of Educational Psychology, 103, 632-648. https://doi.org/10.1037/a0023952.

Fan, X., \& Sivo, S. A. (2007). Sensitivity of fit indices to model misspecification and model types. Multivariate Behavioral Research, 42, 509-529. https://doi.org/10.1080/00273170701382864.

Festinger, L. (1962). A theory of cognitive dissonance, Vol. 2. Standford, CA: Stanford University Press.

Flora, D. B., \& Curran, P. J. (2004). An empirical evaluation of alternative methods of estimation for confirmatory factor analysis with ordinal data. Psychological Methods, 9, 466-491. https://doi.org/10.1037/1082989X.9.4.466.

Fryer, J. W., \& Elliot, A. J. (2007). Stability and change in achievement goals. Journal of Educational Psychology, 99, 700-714. https://doi.org/10.1037/0022-

0663.99.4.700.
Gorges, J., Esdar, W., \& Wild, E. (2014). Linking goal selfconcordance and affective reactions to goal conflict. Motivation and Emotion, 38, 475-484. https://doi.org/ 10.1007/s11031-014-9392-7.

Gorges, J., \& Grund, A. (2017). Aiming at a moving target: Theoretical and methodological approaches to the study of intrapersonal goal conflict. Frontiers in Psychology, 8(2011), https://doi.org/10.3389/fpsyg.2017.02011.

Grant, H., \& Dweck, C. (2003). Clarifying achievement goals and their impact. Journal of Personality and Social Psychology, 85, 541-553. https://doi.org/10.1037/0022-3514.85.3.541.

Hofer, M., \& Fries, S. (2016). A multiple goal perspective on academic motivation. In K. R. Wentzel, \& D. B. Miele (Eds.). Handbook of motivation at school (pp. 440-458). (2nd edition). New York, NY: Taylor Francis.

Hu, L. T., \& Bentler, P. M. (1998). Fit indices in covariance structure modeling: Sensitivity to underparameterized model misspecification. Psychological Methods, 3(4), 424-453.

Hulleman, C. S., Schrager, S. M., Bodmann, S. M., \& Harackiewicz, J. (2010). A meta-analytic review of achievement goal measures: Different labels for the same constructs or different constructs with similar labels? Psychological Bulletin, 136, 422-449. https://doi.org/10.1037/a0018947.

Ismayilova, K., \& Klassen, R. M. (2019). Research and teaching self-efficacy of university faculty: Relations with job satisfaction. International Journal of Educational Research, 98, 55-66. https://doi.org/10.1016/j.ijer.2019.08.012.

Janke, S., Daumiller, M., \& Rudert, S. (2018). Dark pathways to achievement in science: Researchers' achievement goals predict engagement in questionable research practices. Social Psychological and Personality Science Advanced online publication. doi:10/csd5.

Janke, S., \& Dickhäuser, O. (2018). A situated process model of vocational achievement goal striving within members of the academic staff at university. Motivation and Emotion, 42, 1-16. https://doi.org/10.1007/s11031017-9657-z.

Jucks, R., \& Hillbrink, A. (2017). Perspective on research and teaching in psychology: Enrichment or burden? Psychology Learning \& Teaching, 16, 306-322. https://doi. org/10.1177/1475725717705205.

Kehr, H. M. (2004). Implicit/explicit motive discrepancies and volitional depletion among managers. Personality and Social Psychology Bulletin, 30, 315-327. https:// doi.org/10.1177/0146167203256967.

Kenny, D. A., Kaniskan, B., \& McCoach, D. B. (2011). The performance of RMSEA in models with small degrees of freedom. Unpublished paperUniversity of Connecticut. King, R. B., \& McInerney, D. M. (2014). The work avoidance goal construct: Examining its structure, antecedents, and consequences. Contemporary Educational 
Psychology, 39, 42-58.

https://doi.org/10.1016/j.cedpsych.2013.12.002.

Lee, M., \& Bong, M. (2016). In their own words: Reasons underlying the achievement striving of students in schools. Journal of Educational Psychology, 108, 274294. https://doi.org/10.1037/edu0000048.

Leisyte, L., Enders, J., \& de Boer, H. (2009). The balance between teaching and research in Dutch and English universities in the context of university governance reforms. Higher Education, 58, 619-635. https://doi.org/10.1007/s10734-009-9213-1.

Mägi, E., \& Beerkens, M. (2016). Linking research and teaching: Are research-active staff members different teachers? Higher Education, 72, 241-258. https://doi.org/ 10.1007/s10734-015-9951-1.

Markus, H. R., \& Kitayama, S. (1991). Culture and the self: Implications for cognition, emotion, and motivation. Psychological Review, 98, 224-253. https://doi.org/10.1037/0033-295X.98.2.224.

Marsh, H., Muthén, B., Asparouhov, T., Lüdtke, O., Robitzsch, A., Morin, A., et al. (2009). Exploratory structural equation modeling, integrating CFA and EFA. Structural Equation Modeling, 16, 439-476. https://doi.org/10.1080/10705510903008220.

Marsh, H. W., \& Hattie, J. (2002). The relation between research productivity and teaching effectiveness. The Journal of Higher Education, 73, 603-641. https://doi. org/10.1353/jhe.2002.0047.

McAlpine, L., \& Akerlind, G. (2010). Becoming an academic. New York, NY: Macmillan International Higher Education.

Meade, A. W., Johnson, E. C., \& Braddy, P. W. (2008). Power and sensitivity of alternative fit indices in tests of measurement invariance. The Journal of Applied Psychology, 93, 568-592. https://doi.org/10.1037/00219010.93.3.568.

Middleton, M. J., \& Midgley, C. (1997). Avoiding the demonstration of lack of ability: An underexplored aspect of goal theory. Journal of Educational Psychology, 89, 710-739. https://doi.org/10.1037//00220663.89.4.710.

Morales, D. X., Grineski, S. E., \& Collins, T. W. (2017). Faculty motivation to mentor students through undergraduate research programs: A study of enabling and constraining factors. Research in Higher Education, 58, 520-544. https://doi.org/10.1007/s11162-016-9435-x.

Muthén, L., \& Muthén, B. (2017a). Mplus (version 8.1) [Computer Software]. Los Angeles, CA: Muthén \& Muthén. Muthén, L., \& Muthén, B. (2017b). Mplus user's guide (8th ed.). Los Angeles, CA: Muthén \& Muthén.

Murphy, P. K., \& Alexander, P. A. (2000). A motivated exploration of motivation terminology. Contemporary Educational Psychology, 25, 3-53. https://doi.org/10.1006/ceps.1999.1019.
Murayama, K., Elliot, A. J., \& Friedman, R. (2012). Achievement goals. In R. Ryan (Ed.). The oxford handbook of human motivation (pp. 191-207). New York, NY: Oxford University Press.

Nicholls, J. G. (1984). Achievement motivation: Conceptions of ability, subjective experience, task choice, and performance. Psychological Review, 91, 328-346. https://doi.org/10.1037//0033-295x.91.3.328.

Östling, J. (2018). Humboldt and the modern German university. Lund, Sweden: Lund University Press.

Payne, S. C., Youngcourt, S. S., \& Beaubien, J. M. (2007). A meta-analytic examination of the goal orientation nomological net. The Journal of Applied Psychology, 92, 128-150. https://doi.org/10.1037/0021-9010.92.1.128.

Pintrich, P. R. (2000). An achievement goal theory perspective on issues in motivation terminology, theory, and research. Contemporary Educational Psychology, 25, 92 104. https://doi.org/10.1006/ceps.1999.1017.

Praetorius, A.-K., Nitsche, S., Janke, S., Dickhäuser, O., Drexler, K., Fasching, M., \& Dresel, M. (2014). Here today, gone tomorrow? revisiting the stability of teachersä achievement goals. Contemporary Educational Psychology, 39, 379-387. https://doi.org/10.1016/j.cedpsych.2014.10.0020361476X.

Putnick, D. L., \& Bornstein, M. H. (2016). Measurement invariance conventions and reporting: The state of the art and future directions for psychological research. Developmental Review, 41, 71-90. https://doi.org/10.1016/j.dr.2016.06.004.

Rhemtulla, M., Brosseau-Liard, P.É., \& Savalei, V. (2012). When can categorical variables be treated as continuous? A comparison of robust continuous and categorical SEM estimation methods under suboptimal conditions. Psychological Methods, 17, 354-373. https://doi.org/10.1037/a0029315.

Schermelleh-Engel, K., Moosbrugger, H., \& Müller, H. (2003). Evaluating the fit of structural equation models. Methods of Psychological Research Online, 8, 23-74.

Senko, C., \& Dawson, B. (2017). Performance-approach goal effects depend on how they are defined: Meta-analytic evidence from multiple educational outcomes. Journal of Educational Psychology, 109, 574-598. https://doi.org/10.1037/edu0000160.

Sheldon, K. M., \& Elliot, A. J. (1999). Goal striving, need satisfaction, and longitudinal well-being: The self-concordance model. Journal of Personality and Social Psychology, 76(3), 482-497.

Silva, T., \& Nicholls, J. G. (1993). College students as writing theorists: Goals and beliefs about the causes of success. Contemporary Educational Psychology, 18, 281293. https://doi.org/10.1006/ceps.1993.1021.

Simons, D. J. (2014). The value of direct replication. Perspectives on Psychological Science, 9, 76-80. https://doi.org/10.1177/1745691613514755.

Smeby, J.-C. (1998). Knowledge production and knowledge transmission. Teaching in Higher Education, 3, 5-20. 
https://doi.org/10.1080/1356215980030101. Sparfeldt, J. R., Brunnemann, N., Wirthwein, L., Buch, S. R., Schult, J., \& Rost, D. H. (2015). General versus specific achievement goals: A re-examination. Learning and Individual Differences, 43, 170-177. https://doi.org/10.1016/j.lindif.2015.08.022.

Sparfeldt, J. R., Buch, S. R., Wirthwein, L., \& Rost, D. H. (2007). Zielorientierungen: Zur Relevanz der Schulfächer [Goal orientations: The relevance of specific goal orientations as well as specific school subjects]. Zeitschrift für Entwicklungspsychologie und Pädagogische Psychologie/Journal of Developmental and Educational Psychology, 39, 165-176. https://doi.org/10.1026/0049-8637.39.4.165.

Statistisches Bundesamt (2014). Personal an Hochschulen [Personell at higher education institutes]. Retrieved from https://www.destatis.de/DE/Publikationen/ Thematisch/BildungForschungKultur/Hochschulen/PersonalHochschulen2110440137004.pdf.

Stupnisky, R. H., Weaver-Hightower, M., \& Kartoshkina, Y. (2015). Exploring and testing predictors of new faculty success: A mixed method study. Studies in Higher Education, 40, 368-390. https://doi.org/10.1080/03075079.2013.842220.

Stupnisky, R. H., Hall, N. C., Daniels, L. M., \& Mensah, E. (2017). Testing a model of pretenure faculty members' teaching and research success: Motivation as a mediator of balance, expectations, and collegiality. The Journal of Higher Education, 88, 376-400. https://doi.org/10.1080/00221546.2016.1272317.

Urdan, T., \& Mestas, M. (2006). The goals behind performance goals. Journal of Educational Psychology, 98, 354-365. https://doi.org/10.1037/0022-0663.98.2.354. van Dick, R., Schnitger, C., Schwartzmann-Buchelt, C., \& Wagner, U. (2001). Der Job Diagnostic Survey im Bildungsbereich [The job diagnostic survey (JDS) for educational sector occupations]. Zeitschrift für Arbeits- und Organisationspsychologie, 45(2), 74-92.

Wosnitza, M., Helker, K., \& Lohbeck, L. (2014). Teaching goals of early career university teachers in Germany. International Journal of Educational Research, 65, 90103. https://doi.org/10.1016/j.ijer.2013.09.009.

Zhang, L., Fu, M., Li, D. T., \& He, Y. (2019). Emotions and teaching styles among academics: The mediating role of research and teaching efficacy. Educational Psychology, 1-25.

https://doi.org/10.1080/01443410.2018.1520970.

Note. This is a pre-copyedited, author-produced PDF of an article accepted for publication in International Journal of Educational Research following peer review. This paper is not the copy of record and may not exactly replicate the final, authoritative version of the article. The final article will be available, upon publication, via its DOI. 